\title{
Perinatal Salt Restriction: A New Pathway to Programming Insulin Resistance and Dyslipidemia in Adult Wistar Rats
}

\author{
ARMANDO F. VIDONHO, JR., ALEXANDRE A. DA SILVA, SÉRGIO CATANOZI, \\ JUSSARA C. ROCHA, ABRAM BEUTEL, BRUNO A. CARILLO, \\ LUZIA N. SHINOHARA FURUKAWA, RUY R. CAMPOS, \\ CÁSSIA M. DE TOLEDO BERGAMASCHI, ANGELO R. CARPINELLI, EDER C. R. QUINTÃO, \\ MIRIAM S. DOLNIKOFF, AND JOEL C. HEIMANN \\ Laboratory of Experimental Hypertension and Laboratory of Lipids [A.F.V., A.A.d.S., S.C., J.C.R., \\ L.N.S.F., E.C.R.Q., M.S.D., J.C.H.], Department of Internal Medicine, Nephrology Division, University of \\ São Paulo School of Medicine, Brazil, 01246-903; Laboratory of Cardiovascular Physiology [A.B., \\ B.A.C., R.R.C., C.M.d.T.B.], Department of Physiology, Federal University of São Paulo School of \\ Medicine, Brazil, 04023-900; and Laboratory of Insulin Secretion [A.R.C.], Department of Physiology, \\ Institute of Biomedical Sciences of the University of São Paulo, Brazil, 05508-900
}

\begin{abstract}
Several studies support the hypothesis that chronic diseases in adulthood might be triggered by events that occur during fetal development. This study examined the consequences of perinatal salt intake on blood pressure (BP) and carbohydrate and lipid metabolism in adult offspring of dams on high-salt [HSD; 8\% (HSD2) or 4\% (HSD1)], normal-salt (NSD; 1.3\%), or low-salt (LSD; $0.15 \% \mathrm{NaCl}$ ) diet during pregnancy and lactation. At 12 wk of age, female Wistar rats were matched with adult male rats that were fed NSD. Weekly tail-cuff BP measurements were performed before, during, and after pregnancy. After weaning, the offspring received only NSD and were housed in metabolic cages for 24-h urine collection for sodium and potassium and nitrate and nitrite excretion measurements. At $12 \mathrm{wk}$ of age, intra-arterial mean BP was measured, a euglycemic-hyperinsulinemic clamp was performed, and plasma lipids and nitrate and nitrite concentrations were determined. Tail-cuff BP was higher during pregnancy in HSD2 and HSD1 than in NSD and LSD dams. Mean BP (mm Hg) was also higher in the offspring of HSD2 (110 \pm 5$)$ and HSD1 (107 \pm 5$)$ compared with NSD (100 $\pm 2)$ and LSD $(92 \pm 2)$. Lower glucose uptake and higher
\end{abstract}

\section{ABSTRACT}

plasma cholesterol and triacylglycerols were observed in male offspring from LSD dams (glucose uptake: HSD2 $17 \pm 4$, HSD1 $15 \pm 3$, NSD $11 \pm 3$, LSD $4 \pm 1 \mathrm{mg} \cdot \mathrm{kg}^{-1} \cdot \mathrm{min}^{-1}$; cholesterol: HSD2 $62 \pm 6$, HSD1 $82 \pm 11$, NSD $68 \pm 10$, LSD $98 \pm 17$ $\mathrm{mg} / \mathrm{dL}$; triacylglycerols: HSD2 $47 \pm 15$, HSD1 $49 \pm 12$, NSD $56 \pm 19$, LSD $83 \pm 11 \mathrm{mg} / \mathrm{dL})$. In conclusion, maternal salt intake during pregnancy and lactation has long-term influences on arterial pressure, insulin sensitivity, and plasma lipids of the adult offspring. (Pediatr Res 56: 842-848, 2004)
BP, blood pressure
HSD, high-salt diet
HR, heart rate
LSD, low-salt diet
MBP, mean blood pressure
NSD, normal-salt diet
NOx, nitrate plus nitrite
RAS, renin-angiotensin system
tcBP, tail-cuff blood pressure

Abbreviations
Almost two decades ago, Barker and Osmond (1) proposed that ischemic heart disease could be triggered by events that occur during fetal life and early childhood (1). They showed an association between poor living standard during the perinatal period and ischemic heart disease in adulthood. This lifestyle

Received February 11, 2004; accepted June 24, 2004

Correspondence: Joel C. Heimann, M.D., University of São Paulo School of Medicine, Laboratory of Experimental Hypertension, Av. Dr. Arnaldo, 455, 3rd Floor, Room 3342, 01246-903, São Paulo, SP, Brazil; e-mail: jheimann@usp.br

Supported by CAPES (CAPES/CDS/no. 002/2002)

DOI: 10.1203/01.PDR.0000145258.75160.5B possibly goes along with intrauterine growth retardation. Despite criticisms about the validity of their observations (2), the association between low birth weight and adult diseases is now further supported by several studies with similar findings (36). Moreover, the understanding of the mechanisms of this association represents a challenge for investigators in this area.

Intrauterine growth is controlled by a complex interplay of maternal and fetal factors, including circulatory, endocrine, and metabolic systems (7). An increasing number of studies have shown that small modifications in fetal growth may have profound consequences in later life $(8-10)$. 
Protein or caloric restriction of dams during pregnancy and fetal exposure to glucocorticoid excess are the most frequently studied models of intrauterine growth retardation with consequences in adult life, such as hypertension and type 2 diabetes (11-16). Among the few studies on the effect of dietary salt intake during the perinatal period in adult offspring, Contreras et al. (17), using Sprague-Dawley rats, showed that mean arterial pressure is higher in adult offspring from dams that received a high-salt diet during pregnancy. According to the authors, sodium overload during this early period of development may induce important adaptations, especially in the renin-angiotensin system (RAS). In a study performed by Di Nicolantonio et al. (18), lower blood pressure (BP) was observed in adult spontaneous hypertensive rats (SHR) that were born of dams that were fed a sodium-restricted diet during pregnancy. Roy-Clavel et al. (19) also showed that sodium restriction during the perinatal period in Sprague-Dawley rats is related to reduced maternal plasma volume and low birth weight in the offspring (19). However, the possible association between salt intake during the perinatal period and insulin resistance in adult offspring is still an unresolved issue.

To better understand the short- and long-term consequences of dietary $\mathrm{NaCl}$ content during the perinatal period, we evaluated the effects of chronic salt overload and restriction during pregnancy and lactation in Wistar rats on insulin sensitivity in adult offspring. The effects of maternal salt intake during the perinatal period on urinary nitrate and nitrite (NOx) excretion immediately after weaning and on body weight, BP, plasma lipid profile, vascular reactivity, and plasma NOx in adulthood were also measured.

\section{METHODS}

The Ethics Committee of the University of São Paulo School of Medicine, Brazil, approved all experiments herein.

Maternal groups. Female Wistar rats (eight animals per group) from the Institutional Animal Facility were fed a regular rat diet from weaning until $8 \mathrm{wk}$ of age. From thereon, until the end of the experiment, they received a low-salt (LSD; 0.15\% $\mathrm{NaCl}$; Harlan Teklad), normal-salt (NSD; 1.3\%), high-salt 1 (HSD1; 4\%), or high-salt 2 (HSD2; $\%$ NaCl) diet. All diets had $25 \%$ protein content. The animals were housed under controlled conditions of temperature $\left(25^{\circ} \mathrm{C}\right)$ and lighting (lights on at $0600 \mathrm{~h}$ and lights off at $1800 \mathrm{~h}$ ) with free access to food and tap water. Body weight was evaluated once a week since weaning. At $12 \mathrm{wk}$ of age, they were matched with male adults that were fed NSD. Weekly tail-cuff blood pressure (tcBP) measurements were performed before, during, and after pregnancy. Blood samples were collected from the tail vein after overnight fasting before and at the end of each week of gestation for glucose and insulin determinations. For food intake determinations, an additional group of pregnant rats were studied. The animals were housed in metabolic cages at day 10 of gestation. Food intake was measured during $24 \mathrm{~h}$ after 2-3 d of adaptation to the new environment.

Offspring groups. After birth, only eight pups (four male and four female) were kept with their mothers. In the exceeding animals (pups with the lowest and highest birth weight), blood samples were obtained by decapitation, within the first $24 \mathrm{~h}$ after birth in nonfasting condition, for determination of neonatal glucose levels. After weaning, all offspring received NSD. Body weight was evaluated three times a week from birth until weaning and once a week thereafter. Immediately after weaning, some of the offspring was housed in metabolic cages for 24-h urine collection for sodium and potassium and nitrate and nitrite (NOx) excretion measurement. Urine collection was performed in animals with no access to food but with free access to water. $\mathrm{HCl} 6 \mathrm{~N}$ was added to the urine collector to avoid bacterial growth. At $12 \mathrm{wk}$ of age, blood samples were collected from the tail vein after overnight fasting for determination of total cholesterol, triacylglycerols, and NOx levels. Two days after blood collection, catheters were inserted under anesthesia (pentobarbital, $50 \mathrm{mg} / \mathrm{kg}$ body weight) into the jugular vein and carotid artery for blood pressure measurements and to perform a euglycemic-hyperinsulinemic clamp. Vascular reactivity (BP response to phenylephrine) was evaluated in an additional group of offspring.

$\boldsymbol{T} \boldsymbol{c B P}$. TcBP measurements were performed in heated, conscious animals using an oscillometric method (Harvard Indirect Rat Tail Blood Pressure Monitor; Harvard Apparatus Ltd, Edenbridge, Kent, England). All animals were previously trained to become accustomed to the method.

Intra-arterial mean BP. At 12 wk of age, mean $\mathrm{BP}(\mathrm{MBP})$ and heart rate (HR) were measured in conscious, freely moving animals through the carotid artery after $3-5 \mathrm{~d}$ of recovery from the surgery to allow the recovery of presurgical body weight. The catheter was attached to a pressure transducer (model CDX III; Argon Instruments, Athens, TX) that was connected to an amplifier (GPA-4 model 2, Stemtech, Menomonee Falls, WI) that provided the analog BP signal, which was digitized by a computer-based monitoring system (DATAQ Instruments, Akron, $\mathrm{OH})$. The average of MBP determinations during 10 min was used for calculations.

Euglycemic-hyperinsulinemic clamp. On the same day of body weight and MBP determination, a euglycemichyperinsulinemic clamp was performed after $6 \mathrm{~h}$ of fasting with free access to water, in freely moving and conscious animals. Briefly, after blood sample collection for determination of basal glucose and insulin levels, a continuous infusion of regular human insulin $\left(3.0 \mathrm{mU} \cdot \mathrm{kg}^{-1} \cdot \min ^{-1}\right.$; Actrapid, Novo Nordisk A/S) was performed through the jugular catheter during $2 \mathrm{~h}$. Insulin was diluted in $26.61 \mu \mathrm{M}$ of BSA solution. For maintaining serum glucose levels similar to basal values, a glucose infusion (1.11 mM D-glucose) was started 5 min after the beginning of the insulin infusion through the jugular vein. The infusion rate was corrected by a servo-controlled negative feedback principle based on plasma glucose that was measured every 5 min. Plasma insulin determinations were performed at 90,105 , and 120 min after the clamp start for confirmation of the steady state. The amount of glucose infused during the steady state was considered as the peripheral glucose uptake. Experiments in which the coefficient of variation of blood glucose or insulin during the steady state was $>10 \%$ were excluded.

Vascular reactivity. Vascular reactivity was evaluated by changes in MBP and HR after injection of five bolus doses of 
phenylephrine in random order $(0.33,1.0,3.3,10$, and 33 $\mu \mathrm{g} / \mathrm{mL})$ given intravenously $(0.1 \mathrm{~mL})$. Before each injection, baseline of arterial pressure and HR were recorded for at least 10 min. The injections were not repeated until MBP and HR had returned to baseline levels. The doses used represent the midrange of the dose-response curve for phenylephrine based on a previous study (20).

Pancreatic islet isolation and incubation. Rat pancreatic islets were isolated from 12-wk-old male offspring as describe by Lacy and Kostianovsky (21). Three experiments using 10 groups of five islets were performed. The islets were incubated at $37^{\circ} \mathrm{C}$ for $60 \mathrm{~min}$ in $0.5 \mathrm{~mL}$ of Krebs-Henseleit buffer $(115$ $\mathrm{mM}$ of $\mathrm{NaCl}, 24 \mathrm{mM}$ of $\mathrm{NaHCO}_{3}, 5 \mathrm{mM}$ of $\mathrm{KCl}, 1 \mathrm{mM}$ of $\mathrm{MgCl}_{2}$, and $0.2 \mathrm{~g} / \mathrm{dL}$ of BSA). In each experiment, 10 groups were incubated in the presence of $5.6 \mathrm{mM}$ of glucose and 10 groups in the presence of $16.7 \mathrm{mM}$ of glucose. At the end of the experiment, the medium was collected for insulin assay.

Storage of blood samples. All blood samples were centrifuged immediately after collection, and the plasma was collected and stored at $-70^{\circ} \mathrm{C}$ until assayed. Urine samples were stored at $-20^{\circ} \mathrm{C}$.

Data analysis. Urine and plasma NOx concentrations were determined by the Griess reaction after treating the samples with nitrate reductase (22). Plasma glucose concentration was measured using a glucometer (Advantage; Eli Lilly do Brasil Ltda, São Paulo, Brazil). Insulin was measured by RIA kits for rat insulin (Linco Research, St. Charles, MO). Plasma total cholesterol and triacylglycerols were determined by a commercially available kit (Roche Diagnostics, Indianapolis, IN).

Statistical analysis. Values are expressed as means \pm SD. Comparison between two means was made by unpaired $t$ test and between three or more means by one-way ANOVA followed by Tukey post hoc test. The effect of time and salt consumption on body weight and tcBP was evaluated by two-way ANOVA followed by Bonferroni's post hoc test. Slope of tcBP during pregnancy was calculated by linear regression. Null hypothesis was rejected at $p<0.05$.

\section{RESULTS}

Maternal groups. Body weight was not different among maternal groups during the whole follow-up period (Fig. 1); however, tcBP was higher (ANOVA, dietary effect, $p<0.05$ ) before, during, and after pregnancy in HSD1 and HSD2 compared with NSD and LSD groups. The slope of BP's fall during pregnancy was also smaller $(p<0.05)$ in HSD1 and HSD2 than in NSD and LSD groups (Fig. 2).

Daily food intake ( $\mathrm{g} / \mathrm{d}$ per rat) evaluated during the week before mating ( $n=5-10 /$ group) and during the second week of gestation ( $n=6-9 /$ group) showed no differences among the four maternal groups (before pregnancy: HSD2 $14.5 \pm 5.32$, HSD1 $15.2 \pm 2.28$, NSD $15.0 \pm 4.24$, LSD $15.4 \pm 2.30$; during pregnancy: HSD2 $18.0 \pm 2.83$, HSD1 $21 \pm 2.37$, NSD $18.3 \pm 3.04$, LSD $19.3 \pm 1.75$ ).

Fasting plasma glucose and insulin levels were not different among the four groups before pregnancy. However, during the 3 wk of gestation, female rats that received LSD showed higher

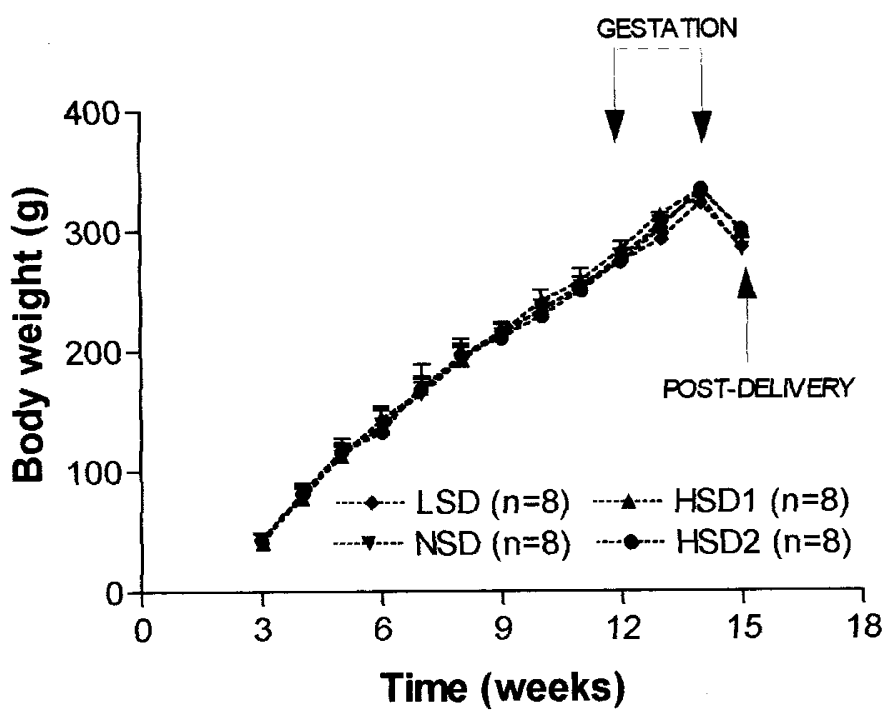

Figure 1. Body weight from $3 \mathrm{wk}$ of age to the end of pregnancy in rats that were fed HSD2, HSD1, NSD, or LSD.

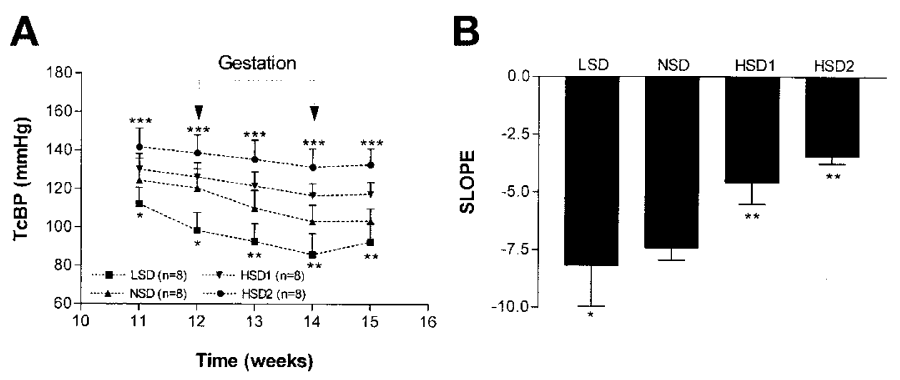

Figure 2. TcBP $(A)$ before, during, and after pregnancy in rats that were fed HSD2, HSD1, NSD, or LSD $(* p<0.05$ LSD $v s$ HSD1 and HSD2; ** $p<0.05$ LSD $v s$ NSD, HSD1, and HSD2; *** $p<0.05$ HSD1 and HSD2 vs NSD). Slope of BP fall $(B)$ during pregnancy in rats that were fed HSD 2, HSD 1, NSD, or LSD $(* p<0.05$ LSD $v s$ HSD1 and HSD2; ** $p<0.05$ HSD1 and HSD2 vs NSD).

$(p<0.05)$ plasma glucose and insulin when compared with the other groups (Table 1).

Offspring groups. Birth weight $(\mathrm{g})$ was lower $(p<0.05)$ in both male and female offspring ( $n=8$ animals/group) from LSD dams compared with the other groups (male rats: HSD2 $6.3 \pm 0.2$, HSD1 $6.5 \pm 0.3$, NSD $6.7 \pm 0.3$, LSD $5.2 \pm 0.3$; female rats: HSD2 $6.2 \pm 0.4$, HSD1 $6.3 \pm 0.5$, NSD $6.6 \pm 0.4$, LSD $5.0 \pm 0.6)$. Neonatal plasma glucose $(\mathrm{mg} / \mathrm{dL})$ was lower $(p<0.05)$ in male offspring from LSD and NSD compared with HSD2 and HSD1 groups (male rats: HSD2 $76 \pm 10, n=$ 10; HSD1 $78 \pm 7.6, n=9$; NSD $61 \pm 8, n=15$; LSD $57 \pm$ $7.8, n=8$ ). No differences between groups were observed among female offspring (female rats: HSD2 $74 \pm 12, n=9$; HSD $13 \pm 12, n=11 ; \operatorname{NSD} 70 \pm 11, n=11 ; \operatorname{LSD} 70 \pm 6$ $n=8)$.

Body weight evaluated three times a week, from birth until weaning, was lower in male LSD offspring at 3, 5, 8, and $21 \mathrm{~d}$ of life (Fig. 3). Body weight was also lower in female LSD offspring at 3, 5, 8, 10, 12, 15, and $17 \mathrm{~d}$ of life (Fig. 3). Body weight $(\mathrm{g})$ evaluated at $12 \mathrm{wk}$ of age ( $n=6$ /group) was similar among the four dietary groups (male rats: HSD2 $432 \pm 28$, HSD1 $425 \pm 30$, NSD $430 \pm 17$, LSD $440 \pm 15$; female rats: 
Table 1. Blood glucose and plasma insulin before and during weeks 1, 2, and 3 of gestation in wistar rats that were fed HSD2, HSD1, $N S D$, or LSD

\begin{tabular}{|c|c|c|c|c|}
\hline Parameters & $\operatorname{LSD}(n=4)$ & $\operatorname{NSD}(n=4)$ & $\operatorname{HSD} 1(n=9)$ & $\operatorname{HSD} 2(n=4)$ \\
\hline \multicolumn{5}{|c|}{ Glucose $(\mathrm{mg} / \mathrm{dL})$} \\
\hline Pregestation & $85.5 \pm 2$ & $74 \pm 12$ & $77.5 \pm 2$ & $77.2 \pm 5$ \\
\hline Week 1 & $93.5 \pm 15^{*}$ & $72.6 \pm 9$ & $77 \pm 3.5$ & $79.2 \pm 6.3$ \\
\hline Week 3 & $116 \pm 3^{*}$ & $73 \pm 11$ & $81 \pm 18$ & $83 \pm 6$ \\
\hline \multicolumn{5}{|l|}{ Insulin (pmol/L) } \\
\hline Pregestation & $647 \pm 39$ & $649 \pm 32$ & $669 \pm 21$ & $635 \pm 37$ \\
\hline Week 3 & $900 \pm 38.6^{*}$ & $774 \pm 24$ & $784 \pm 26$ & $771 \pm 41$ \\
\hline
\end{tabular}

Data are presented as mean \pm SD.

$* p<0.05$ vs. NSD, HSD1, and HSD2.

A)

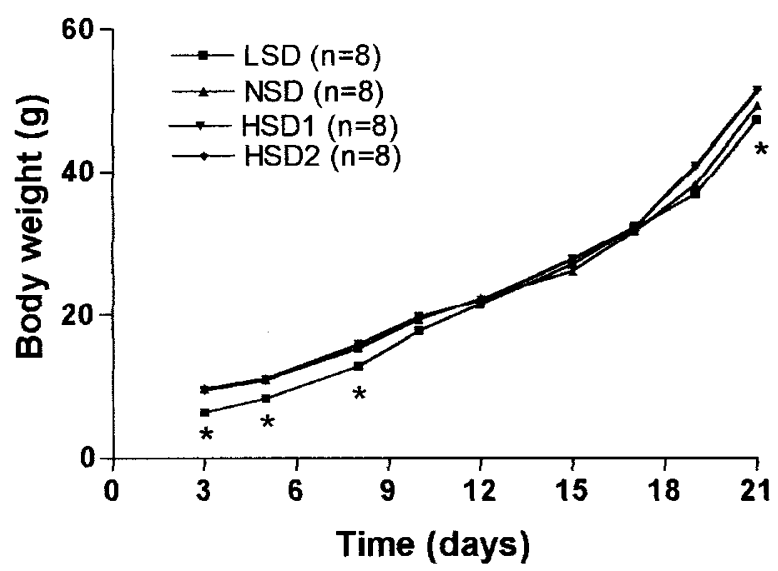

B)

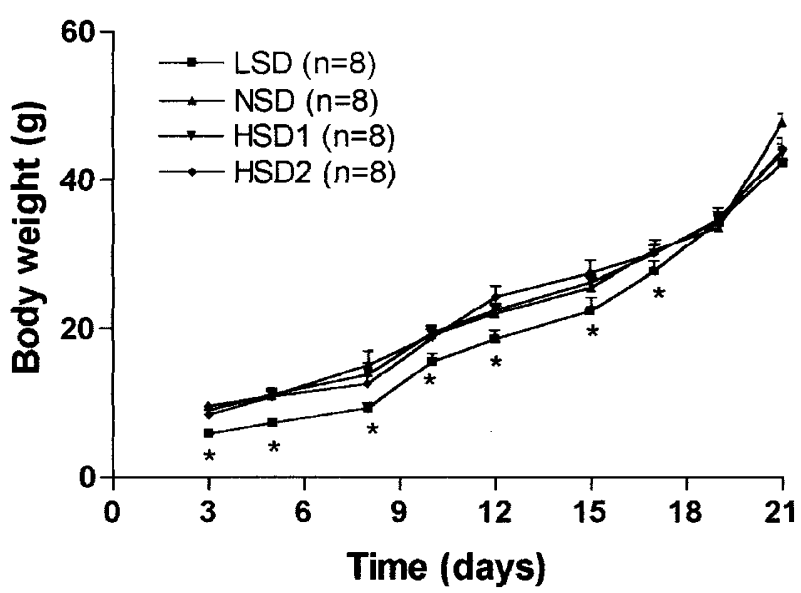

Figure 3. Body weight evaluated three times a week, from birth until weaning, in male $(A)$ and female $(B)$ offspring $\left({ }^{*} p<0.05\right.$ vs NSD, HSD1, and HSD2).

HSD2 $285 \pm 18$, HSD1 $288 \pm 19$, NSD $286 \pm 19$, LSD 272 \pm 17 .

Twenty-four-hour urinary sodium excretion was lower $(p<$ $0.05)$ and 24-h urinary potassium excretion was higher $(p<$
0.05 ) in male and female offspring from LSD dams at 3 wk of age compared with NSD, HSD1, and HSD2 groups, whereas NOx urinary excretion was higher $(p<0.05)$ in male and female HSD2 compared with NSD offspring (Table 2).

Intra-arterial mean BP $(n=8$ /group, $\mathrm{mm} \mathrm{Hg})$, evaluated at $12 \mathrm{wk}$ of age, was directly proportional to the amount of salt in the diet during pregnancy and lactation, being higher $(p<$ $0.05)$ in male and female offspring of HSD2 and HSD1 groups and lower $(p<0.05)$ in male and female offspring of the LSD group (male rats: HSD2 $110 \pm$ 5, HSD1 $107 \pm$ 5, NSD $100 \pm$ 2, LSD $92 \pm 2$; female rats: HSD2 $112 \pm 5$, HSD1 $110 \pm 3$, NSD $103 \pm 3$, LSD $98 \pm 4$ ).

In male offspring, glucose uptake $\left(\mathrm{mg} \cdot \mathrm{kg}^{-1} \cdot \mathrm{min}^{-1}\right)$, a measure of insulin sensitivity, evaluated at $12 \mathrm{wk}$ of age also showed a direct association with the amount of salt consumed by the mothers, being lower $(p<0.05)$ in the LSD group and a tendency for higher glucose uptake in the HSD2 group when compared with the other groups. No differences in insulin sensitivity were observed among the female groups (Fig. 4).

Higher plasma cholesterol and triacylglycerols $(p<0.05$, $\mathrm{mg} / \mathrm{dL}$ ) were detected in male LSD offspring (cholesterol: HSD2 $62.4 \pm 6.4$, HSD1 $81.8 \pm 11$, NSD $68.0 \pm 9.5$, LSD $98.1 \pm 17.2$; triacylglycerols: HSD2 $46.7 \pm 14.7$, HSD1 49.4 \pm 12 , NSD $56.2 \pm 19$, LSD $82.5 \pm 10.6$ ). No differences, however, were detected among female rats (cholesterol: HSD2 $81 \pm 7$, HSD1 $81 \pm 12$, NSD $71 \pm 14$, LSD $78 \pm 21$; triacylglycerols: HSD2 $70 \pm 14$, HSD1 $73 \pm 16$, NSD $69 \pm$ 19 , LSD $74 \pm 27$ ). Plasma NOx $(n=8 /$ group, $\mu \mathrm{mol} / \mathrm{L})$ were not influenced by the dietary salt content during pregnancy and lactation (male rats: HSD2 $43.4 \pm 4$, HSD1 $42.6 \pm 9$, NSD $44.2 \pm 6$, LSD $44.2 \pm 6$; female rats: HSD2 $47.3 \pm 4$, HSD1 $44.7 \pm 5$, NSD $43.8 \pm 3$, LSD $42.1 \pm 4$ ).

The vascular reactivity (BP increase, $\mathrm{mm} \mathrm{Hg}$ ), evaluated in 12-wk-old offspring, was also not influenced by the degree of perinatal salt consumption, both in male ( $n=3-4$ /group) and female rats ( $n=4-7 /$ group; male rats: $0.33 \mu \mathrm{g} / \mathrm{mL}$ : LSD $25 \pm$ 15, NSD $33 \pm 1$, HSD1 $21 \pm 8$, HSD2 $27 \pm 17 ; 3.3 \mu \mathrm{g} / \mathrm{mL}$ : LSD $52.1 \pm 15$, NSD $58 \pm 12$, HSD1 $60 \pm 4$, HSD2 $51 \pm 28$ $33 \mu \mathrm{g} / \mathrm{mL}:$ LSD $68 \pm 6$, NSD $78 \pm 14$, HSD1 $72 \pm 5$, HSD2 $67 \pm 15 \mathrm{~mm} \mathrm{Hg}$; female rats: $0.33 \mu \mathrm{g} / \mathrm{mL}:$ LSD $33 \pm 15$, NSD $36 \pm 12, \mathrm{HSD} 126 \pm 6, \mathrm{HSD} 235 \pm 14 ; 3.3 \mu \mathrm{g} / \mathrm{mL}: \mathrm{LSD} 64$ \pm 9 , NSD $59 \pm 12$, HSD $159 \pm 12, \mathrm{HSD} 255 \pm 4 ; 33 \mu \mathrm{g} / \mathrm{mL}:$ LSD $82 \pm 7$, NSD $75 \pm 8$, HSD1 $82 \pm 12$, HSD2 $71 \pm 15)$. 
Table 2. Twenty-four-hour urinary sodium, potassium, and NOx excretion in offspring of 3 weeks of age from dams that were fed HSD2, HSD1, NSD, or LSD during pregnancy and lactation

\begin{tabular}{|c|c|c|c|c|}
\hline Parameters & $\operatorname{LSD}(n=8)$ & $\operatorname{NSD}(n=8)$ & HSD1 $(n=8)$ & $\operatorname{HSD} 2(n=8)$ \\
\hline \multicolumn{5}{|l|}{ Male offspring } \\
\hline Urinary $\mathrm{Na}^{+}(\mu \mathrm{Eq})$ & $6.3 \pm 3.5^{*}$ & $37.8 \pm 15.7$ & $93 \pm 17 \dagger$ & $170 \pm 23 \dagger$ \\
\hline Urinary $\mathrm{K}^{+}(\mu \mathrm{Eq})$ & $213 \pm 26^{*}$ & $113 \pm 44$ & $57 \pm 17 \dagger$ & $55.7 \pm 15 \dagger$ \\
\hline \multicolumn{5}{|l|}{ Female offspring } \\
\hline Urinary $\mathrm{Na}^{+}(\mu \mathrm{Eq})$ & $7.2 \pm 3^{*}$ & $40.8 \pm 21$ & $97 \pm 25 \dagger$ & $135 \pm 50 \dagger$ \\
\hline Urinary $\mathrm{K}^{+}(\mu \mathrm{Eq})$ & $220 \pm 27 *$ & $117.4 \pm 44$ & $53.7 \pm 13 \dagger$ & $45.7 \pm 8.5 \dagger$ \\
\hline
\end{tabular}

Data are presented as mean \pm SD.

$* p<0.05$ vs. NSD, HSD1, and HSD2.

$\dagger p<0.05$ vs. NSD.

$\ddagger p<0.05$ vs. LSD and NSD.

A)
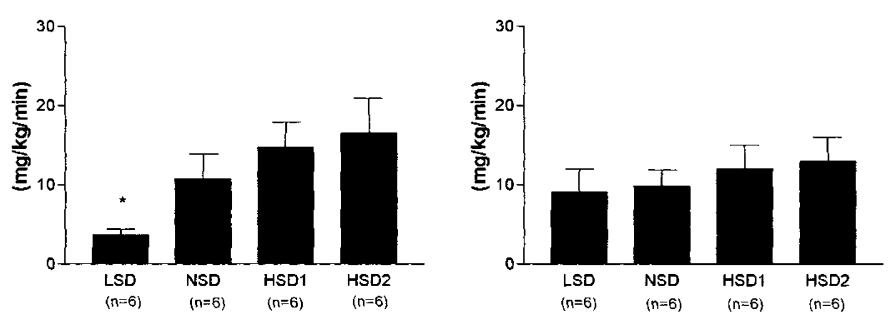

Figure 4. Insulin sensitivity in male $(A)$ and female $(B)$ offspring from dams that were fed HSD2, HSD1, NSD, or LSD $(* p<0.05$ vs NSD, HSD1, and HSD2).

The amount of insulin secreted ( $n=23$ /group, \% change, $\mathrm{pmol} / \mathrm{L})$ by isolated pancreatic islets in response to a glucose challenge was reduced $(p<0.0001)$ in male LSD offspring compared with male HSD2 offspring (HSD2 $39.1 \pm 29.5$, LSD $15.4 \pm 11.2)$.

\section{DISCUSSION}

The main new findings of the present study are that male offspring from dams that are fed an LSD during pregnancy and lactation have lower insulin sensitivity and higher plasma cholesterol and triacylglycerols compared with the offspring from mothers that are fed NSD or HSD. In addition, a higher BP was observed in adult male and female offspring of dams that consumed HSD compared with the other groups.

Male and female LSD offspring disclosed lower birth weights compared with the offspring of the other experimental groups. Low birth weight for gestational age is a sign of restricted offer of nutrients or oxygen to the fetus, which responds with slower cell division during critical periods of prenatal life (23). The reduced delivery of nutrients and oxygen to the fetus may be related to maternal undernutrition (24) or to hemodynamic factors involving the uteroplacental complex (25). In this study, no differences were observed in body weight among the maternal groups during pregnancy, indicating the absence of malnourishment of the dams that were fed LSD.

A possible link between maternal low salt intake during pregnancy and offspring low birth weight could be the activation of maternal RAS $(26,27)$. It is known that angiotensin II inhibits trophoblast invasion, which could compromise placental function and fetal nutrition (28), leading to reduced weight at birth. In addition, Holcberg et al. (29) showed that angiotensin II increases tumor necrosis factor- $\alpha$ in the perfusate of isolated cotyledons from normal fetuses. Tumor necrosis factor- $\alpha$ is a known powerful proinflammatory cytokine that may contribute to vasoconstriction of placental vascular bed and consequent fetal ischemia (29). Therefore, these mechanisms may be an explanation for the low birth weight in this group.

In addition to the RAS activation, low salt intake increases sympathetic nervous system activity (30), which could also provoke hemodynamic changes in the uteroplacental circulation, compromising fetal nutrition. A third effect of salt restriction that may also contribute to affect fetal nutrition is a decrease of extracellular volume and tissue perfusion including the uteroplacental complex (19). Finally, it was also reported that the L-arginine-nitric oxide pathway activity is inhibited by low salt intake (31). This effect may compromise placental perfusion with deleterious effects on the fetus. Therefore, several mechanisms may possibly be involved in poor fetal nutrition as a result of salt restriction during pregnancy.

Higher urinary sodium and lower urinary potassium excretion were observed on the day of weaning in male and female HSD1 and HSD2 compared with NSD and LSD offspring. Differences in the amount of milk consumed or milk sodium and potassium concentration can be ruled out as responsible for the observed differences in offspring electrolyte urinary excretion. Differences in the amount of milk consumption would affect sodium and potassium excretion in the same directions and not in opposite directions as observed. However, considering that milk consumption probably is similar among groups, sodium concentration in the milk of HSD2 dams should be 19to 27-fold higher than in the milk from LSD dams to explain the differences in urinary excretion. To our knowledge, no mechanisms in the mammary gland are able to produce milk with such differences in electrolyte composition. Therefore, a possible explanation left is that offspring consumed their mother's diet, at least during the final period of lactation. If this is true, then some consequences of low or high salt intake in lactating offspring may be responsible for lifelong functional changes. Stimulation of the RAS and the sympathetic nervous system and inactivation of the L-arginine-nitric oxide pathway as a result of salt restriction and the opposite in response to salt 
overload are some of the mentioned consequences. In 3-wk-old rats, it is difficult to obtain enough blood volume to evaluate circulating RAS and L-arginine-nitric oxide pathway activity. Therefore, we decided to measure 24-h urinary NOx excretion that was elevated in HSD2 male and female rats in accordance with other studies. Further studies are needed to verify whether there is a functional link between changes in L-arginine-nitric oxide pathway activity early in life and the observed changes in BP and carbohydrate and lipid metabolism in adult rats. Adult LSD offspring have the lowest insulin sensitivity and reduced pancreatic insulin secretion in response to a glucose challenge. The results of peripheral glucose uptake may not represent the real metabolic phenomenon, once hepatic glucose output was not evaluated. However, this possibility is highly unlikely because hepatic glucose release is inhibited by high circulating insulin concentration. Garafano et al. (32) showed a reduced $\beta$-cell mass at birth in the offspring of mothers who were subjected to food restriction during late pregnancy. The authors also showed that subsequent renutrition was followed by increased $\beta$-cell proliferation but insufficient to fully restore the $\beta$-cell mass. Because $\beta$-cells have a limited capacity to reproduce after weaning in rats (33) and after any postnatal period in humans (34), fetal and early postnatal undernutrition could lead to permanent changes in carbohydrate and insulin metabolism. Taking together, these observations suggest that inhibition of insulin release from pancreatic islets of the male offspring of low-salt dams could be caused, at least in part, by reduced delivery of nutrients to the fetus, but additional studies are needed to test this possibility.

Glucose and insulin levels during pregnancy were higher in dams that were on LSD compared with dams that were on NSD or HSD, thus suggesting lower insulin sensitivity similar to what already has been shown in male rats $(35,36)$. Because of higher plasma levels of glucose and insulin, a higher birth weight in the offspring of LSD dams was expected, similar to what is observed in diabetic mothers. However, it has to be pointed out that although dams on LSD are insulin resistant, they do not disclose glucose levels above normal. Moreover, the higher body weight in neonates of diabetic mothers is mainly caused by the high fetal insulin levels in response to elevated plasma glucose transmitted by the mother (37). Therefore, despite that insulin levels were not measured in neonates, the mechanisms of higher body weight in neonates of diabetic mothers are possibly not operative in the model evaluated in the present study.

Birth weight was lower in male and female offspring from LSD dams. A phenomenon known as "catch-up growth" occurred because no differences in body weight were observed in 12 -wk-old offspring. This phenomenon has been suggested to be associated with obesity and type 2 diabetes in adult life (38) and could be a contributing mechanism involved in the insulin resistance observed in male adult offspring of LSD dams.

The differences between male and female offspring of dams that were fed LSD during gestation are a very interesting finding of this study. However, the present study was not designed to elucidate the possible mechanisms for the observed sexual dimorphism, and new studies are necessary to elucidate this phenomenon.
Confirming previous observations (39), in the present study, salt overload during pregnancy and lactation was associated with higher BP in adult offspring. The mechanisms that lead to increased BP in this experimental model are still not well understood, and further studies are needed to unravel them. A functional change of the RAS may be a possible explanation for the higher MBP observed in adult offspring of salt-overloaded dams. Silva et al. (39), using a similar experimental model, detected higher renal angiotensin II content in the offspring from HSD2 dams. This enhanced renal angiotensin II could affect the pressure natriuresis setpoint, which could result in a shift of the pressure natriuresis relationship toward higher BP.

\section{CONCLUSION}

In summary, this study has shown a new association among perinatal salt restriction, low birth weight, and insulin resistance in adulthood. This finding suggests that LSD during pregnancy and lactation possibly influences fetal development and may be responsible for diseases in adult life.

Acknowledgments. We thank Marlene S. Rocha for technical assistance in the pancreatic islets study.

\section{REFERENCES}

1. Barker DJ, Osmond C 1986 Infant mortality, childhood nutrition, and ischaemic heart disease in England and Wales. Lancet 1:1077-1081

2. Paneth N, Ahmed F, Stein AD 1996 Early nutritional origins of hypertension: a hypothesis still lacking support. J Hypertens Suppl 14:S121-S129

3. Law CM, Shiell AW 1996 Is blood pressure inversely related to birth weight? The strength of evidence from systematic review of the literature. J Hypertens 14:935-941

4. Leon DA, Lithell HO, Vagero D, Koupilova I, Mohsen R, Berglund L, Lithell UB, McKeigue PM 1998 Reduced fetal growth rate and increased risk of death from ischaemic heart disease: cohort study of 15000 Swedish men and women born 1915-29. BMJ 317:241-245

5. Stein CE, Fall CH, Kumaran K, Osmond C, Cox V, Barker DJ 1996 Fetal growth and coronary artery disease in South India. Lancet 348:1269-1273

6. Rich-Edwards JW, Stampfer MJ, Manson JE, Rosner B, Hankinson SE, Colditz GA, Willet WC, Hennekens CH 1997 Birth weight and risk of cardiovascular disease in a cohort of women followed up since 1976. BMJ 315:396-400

7. Byrne CD, Phillips DI 2000 Fetal origins of adult disease: epidemiology and mechanisms. J Clin Pathol 53:822-828

8. Law C 1995 Fetal influences on adult hypertension. J Hum Hypertens 9:649-651

9. Law CM, Barker DJ 1994 Fetal influences on blood pressure. J Hypertens 12:1329_ 1332

10. Law CM, de Swiet M, Osmond C, Fayers PM, Barker DJ, Cruddas AM, Fall CH 1993 Initiation of hypertension in utero and its amplification throughout life. BMJ 306:24-27

11. Langley SC, Jackson AA 1994 Increased systolic blood pressure in adult rats induced by fetal exposure to maternal low protein diet. Clin Sci (Lond) 86:217-222

12. Roseboom TJ, van der Meulen JH, Osmond C, Barker DJ, Ravelli AC, Bleker OP 2001 Adult survival after prenatal exposure to the Dutch famine 1944-45. Paediatr Perinat Epidemiol 15:220-225

13. Roseboom TJ, van der Meulen JH, Ravelli AC, Osmond C, Barker DJ, Bleker OP 2001 Effects of prenatal exposure to the Dutch famine on adult disease in later life: an overview. Mol Cell Endocrinol 185:93-98

14. Benediktsson R, Lindsy RS, Noble J, Seckl JR, Edwards CR 1993 Glucocorticoids exposure in utero: new model of adult hypertension. Lancet 341:339-341

15. Gardner DS, Jackson AA, Langley-Evans SC 1997 Maintenance of maternal dietinduced hypertension is dependent on glucocorticoids. Hypertension 30:1525-1530

16. Langley-Evans SC 1997 Intrauterine programming of hypertension by glucocorticoids. Life Sci 60:1213-1221

17. Contreras RJ, Wong DL, Henderson R, Curtis KS, Smith JC 2000 High dietary NaCl early in development enhances mean arterial pressure of adult rats. Physiol Behav 71:173-181

18. Di Nicolantonio R, Hoy K, Spargo S, Morgan TO 1990 Perinatal salt intake alters blood pressure and salt balance in hypertensive rats. Hypertension 15:177-182

19. Roy-Clavel E, Picard S, St-Louis J, Brochu M 1999 Induction of intrauterine growth restriction with a low-sodium diet fed to pregnant rats. Am J Obstet Gynecol 180:608-613

20. Ito S, Gordon FJ, Sved AF 1999 Dietary salt intake alters cardiovascular responses evoked from the rostral ventrolateral medulla. Am J Physiol 276:R1600-R1607

21. Lacy PE, Kostianovsky M 1967 Method for isolation of intact islets of Langerhans from the rat pancreas. Diabetes 16:35-39 
22. Schimdt HHHW, Kelm H 1996 Determination of nitrite and nitrate by the Gries reaction. In: Feelisch M, Stamler JS (eds) Methods in Nitric Oxide Research. John Wiley \& Sons, West Sussex, pp 491-497

23. Barker DJ 1996 The fetal origins of hypertension. J Hypertens Suppl 14:S117-S120

24. Molina-Font JA 1998 Nutrition and fetal growth. Early Hum Dev 53:S51-S60

25. Lang U, Baker RS, Braems G, Zygmunt M, Kunzel W, Clark KE 2003 Uterine blood flow-a determinant of fetal growth. Eur J Obstet Gynecol Reprod Biol 110:S55-S61

26. Binder ND, Laird MR, Faber JJ 1995 Interrelationships between the renin angiotensin system and uteroplacental blood flow - a recent perspective. Reprod Fertil Dev 7:1437-1442

27. Hagemann A, Nielsen AH, Poulsen K 1994 The uteroplacental renin-angiotensin system: a review. Exp Clin Endocrinol 102:252-261

28. Xia Y, Wen HY, Kellems RE 2002 Angiotensin II inhibits human trophoblast invasion through AT1 receptor activation. J Biol Chem 277:24601-24608

29. Holcberg G, Huleihel M, Sapir O, Katz M, Tsadkin M, Furman B, Mazor M, Myatt L 2001 Increased production of tumor necrosis factor- $\alpha$ TNF- $\alpha$ by IUGR human placentae. Eur J Obstet Gynecol Reprod Biol 94:69-72

30. Folkow B, Ely DL 1987 Dietary sodium effects on cardiovascular and sympathetic neuroeffector functions as studied in various rat models. J Hypertens 5:383-395

31. Boonstra AH, Gschwend S, Kocks MJ, Buikema H, de Zeeuw D, Navis GJ 2001 Does a low-salt diet exert a protective effect on endothelial function in normal rats? J Lab Clin Med 138:200-205
32. Garofano A, Czernichow P, Breant B $1998 \beta$-cell mass and proliferation following late fetal and early postnatal malnutrition in the rat. Diabetologia 41:1114-11120

33. Fowden AL, Hill DJ 2001 Intra-uterine programming of the endocrine pancreas. $\mathrm{Br}$ Med Bull 60:123-142

34. Holemans K, Aerts L, Van Assche FA 2003 Fetal growth restriction and consequences for the offspring in animal models. J Soc Gynecol Investig 10:392-399

35. da Costa Lima NK, Lima FB, dos Santos EA, Okamoto MM, Matsushita DH, Hell NS, Heimann JC 1997 Chronic salt overload increases blood pressure and improves glucose metabolism without changing insulin sensitivity. Am J Hypertens 10:720727

36. Prada P, Okamoto MM, Furukawa LN, Machado UF, Heimann JC, Dolnikoff MS 2000 High- or low-salt diet from weaning to adulthood: effect on insulin sensitivity in Wistar rats. Hypertension 35:424-429

37. Mello G, Parretti E, Mecacci F, Lucchetti R, Lagazio C, Pratesi M, Scarselli G 1997 Risk factors for fetal macrosomia: the importance of a positive oral glucose challenge test. Eur J Endocrinol 137:27-33

38. Hales CN, Ozanne SE 2003 The dangerous road of catch-up growth. J Physio 547:5-10

39. da Silva AA, de Noronha IL, de Oliveira IB, Malheiros DM, Heimann JC 2003 Renin-angiotensin system function and blood pressure in adult rats after perinatal salt overload. Nutr Metab Cardiovasc Dis 13:133-139 